\title{
A estética de \\ Frederico Nietzsche ${ }^{* *}$
}

\author{
Leonardo Mascello*
}

\begin{abstract}
Resumo: Artigo publicado no Jornal do Recife, a 10 de Novembro de 1911. Nele, o autor se mostra motivado a escrever sobre Nietzsche por causa das inúmeras publicações a seu respeito, como a biografia trazida ao público pela irmã do filósofo, Elisabeth Förster. Discorre assim apenas rapidamente acerca da vida do filósofo, uma vez que seu objetivo é apontar na sua estética alguns defeitos e equívocos. Passa então a uma abordagem da obra Origens da tragédia recorrendo aos trabalhos de Ettore G. Zoccoli e Attillio Corsi.
\end{abstract}

Palavras-chave: Nietzsche - estética - Origens da tragédia

Todo o mundo fala deste estranho filósofo do século passado, nascido em 15 de outubro de 1844 na cidade de Röcken, perto de Lützen; cujo nome tornou-se celebre não porque ele fosse um grande pensador, um grande poeta ou um gênio universal; mas justamente pelo contrário, isto é, por ter em diversos livros, apregoado ideias impossíveis, elucubrações monstruosas, paradoxos formidáveis e às vezes de uma crueldade brutal. Entretanto não é raro aos nossos dias ouvir falar, literatos e eróticos, com entusiasmo, de Frederico Nietzsche, proclamando serem-lhe discípulos, admiradores, turiferários; gloriando-se de lhe sacrificar como a um nome.

O público, ou melhor, os poucos que leem os artigos literários, o mais das vezes, se contentam com um ou dois nomes difíceis para se persuadir de que o autor é um erudito, etc; porém, quando

* Publicado no Jornal do Recife. Pernambuco, 10 de Novembro de 1911, p. 01. ** Padre. 
Mascello, L.

encontraram o nome de Frederico Nietzsche, esforçam-se para pronunciar uma ou duas vezes a palavra misteriosa e achando-a muito áspera e difícil fazem careta como quem mastiga uma fruta azeda e depois ficam na convicção de que se trata de um gênio muito árduo, descomunal e maravilhoso! E assim o jovem crítico, rapaz intelectual e talentoso, que rabisca as suas impressões para o jornalismo indulgente, não deixa escapar ocasião nenhuma sem protestar a admiração para d'Annunzio, Wilde, Carlyle, Maeterlinck e Nietzsche, julgando com isto dar um valor sério extraordinário à sua prosinha.

Elisabeth Förster-Nietzsche, irmã de Frederico, compilou uma biografia do filósofo do super-homem que em parte foi publicada nestes últimos anos. Ali se leem as seguintes notícias: “Nasci em 15 de Outubro de 1844 em Röcken, perto de Lützen, recebi no santo batismo os nomes de Frederico Willem. Meu pai era pastor evangélico, tipo perfeito do ministro de aldeia".

$\mathrm{Na}$ mesma autobiografia, Nietzsche declara ter tido desde criança uma certa inclinação para o sossego e o silêncio, vivendo quase afastado dos outros meninos. Com apenas nove anos de idade já era um grande sonhador; e tendo ouvido um "Alleluja" de Jorge Handel, teve vontade de compor quanto antes uma peça igual.

Em 1850 morreu-lhe o pai e passou com a família para Naumburg e dali seguiu para o colégio de Pforta, onde começou a escrever a própria autobiografia. Os críticos de Nietzsche explicam o facto de não ter ele compilado um verdadeiro sistema de filosofia ou de filologia devido à extraordinária intensidade com que se aplicava às construções abstratas, apelando com um esforço excepcional e por conseguinte pouco contraste para todas as energias e aptidões da sua inteligência. Pelo que acontecia que ele dava a cada uma das suas especulações metafísicas uma relativa perfeição que lhe impedia de revelá-las e amplificá-las e deduzir delas outras consequências. Porém sempre teve uma inabalável confiança no seu gênio e também foi de uma sinceridade destemida, de tal sorte que muitas vezes contradisse às próprias teorias com a mesma veemência com que atacava aos adversários, sem com isso cessar 
de apregoar com convicção e a ardência de um apostolo novo e mais estranhos paradoxos.

Convencido de ser um dos mais dignos representantes da raça slava, embora às vezes experimentasse íntimos desalentos, não podia, contudo admitir que se lhe opusessem barreiras sobre o seu caminho, senão para superá-las vitoriosamente. Espírito irrequieto e sempre descontente, por uma íntima e invencível inclinação ao pessimismo e por uns misteriosos constrangimentos que envenenavam a sua alma dolorida, ele não encontrava sossego em parte nenhuma e mudava facilmente de vida e de ideias. E, com efeito, depois de formado, sentou praça no exército tomando parte em diversas batalhas em 1870; aborrecido com os horrores da guerra retirou-se à vida privada até que foi nomeado lente de filologia clássica na universidade de Basileia.

Bem cedo porém não quis saber mais da vida acadêmica e renunciando a cadeira voltou à vida livre, entregando-se completamente aos seus estudos e às suas especulações filosóficas.

Não é meu intuito aqui fazer uma exposição dos erros, absurdos, paradoxos, negações históricas, invectivas, de que estão repletos os livros de Frederico Nietzsche.

Muitos críticos já fizeram isto e quase todos eles estão de acordo em lastimar um tão infeliz gasto de energias intelectivas em apregoar máximas e aforismos tão absurdos e inumanos. Quero apenas tocar na sua estética apontando ligeiramente os defeitos e equívocos que ali se encontram.

É sabido que em nenhuma das obras de Nietzsche há continuidade harmônica de exposição ou de investigação, a não ser nas Origens da tragédia, o único livro dele que apresenta um desenvolvimento progressivo de uma teoria, até tornar-se quase um tratado.

Os críticos dividem as concepções crítico-estéticas de Nietzsche em dois períodos: um pro e outro contra Wagner.

No primeiro ele tentou fazer uma exegese apologética dos problemas estéticos propostos e resolvidos por Wagner na sua obra Oper und Drama. 
Mascello, L.

Este célebre músico e filósofo, nas suas obras estéticas, seguiu e defendeu com grande ardor e convicção as teorias de Schopenhauer sobre a música, na qual, segundo este, é preciso reconhecer não uma ideia particular e determinada; mas a ideia mesma do mundo. Entretanto Nietzsche a princípio aderiu à teoria schopenhaueriana e ao seu pessimismo, apreciando-o através das obras de Wagner; porém quando julgou ter destruído a concepção pessimista do mundo, como esta se encontra nas obras do filósofo do Dionisíaco, ele se revelou a Wagner e a Schopenhauer e seguiu um caminho todo seu.

A primeira obra de Nietzsche: Dei Geburt der Tragódie trata de alguns problemas fundamentais da estética e dá uma solução deles absolutamente original e fantástica, que se insinua depois em toda a sua produção estética e ética posterior (Zoccoli: Frederico Nietzsche, pag. 2011).

Escrevendo este livro de filosofia da arte, observa Attillio Corsi no prefácio à tradução italiana da sobredita obra, Nietzsche queria apontar no culto da beleza o único refúgio contra a vida, à única possibilidade de paz.

Qual povo teria podido servi-lhe de modelo, para demonstrar isso, melhor do que o povo grego?

Segundo Nietzsche o mundo pode ser considerado como um fenômeno estético, como na espécie de obra de arte, da qual o seu criador atinge uma alegria estética suprema; e o indivíduo por sua vez torna-se artista por meio de uma vida criadora. Este último pode com efeito criar já diretamente, como artista; já indiretamente por meio da contemplação de uma obra de arte que evoca poderosamente a sua visão interior e certas imagens do mundo exterior e que lhe procuram um gozo estético. $\mathrm{O}$ essencial de um ato estético é a criação de uma imagem interior, isto é, uma visão, um sonho do mundo exterior, não só daquilo que é mais belo, mas também daquilo que é mais imponente e doloroso na vida.

Frederico Nietzsche chama faculdade apolínea a possibilidade de criar imagens da vida real. Com esta possibilidade o homem 
pode subtrair-se do pessimismo refugiando-se para a contemplação da beleza. Porém o homem tem uma dupla consciência: individual e Universal. Com a primeira ele repara o seu ser indivíduo; com a segunda sente que é parte daquela Vontade schopenhaueriana (Wille) que o próprio filósofo supunha difusa e imperante por todo o universo. Por esta segunda consciência o homem começa a simpatizar com tudo aquilo que vive e sofre; e então no êxtase da contemplação e da admiração esquece a própria individualidade que o separa do resto do mundo e coloca a própria personalidade na natureza, que não é senão a Wille de Schopenhauer. Neste segundo caso temos o estado dionisíaco, cuja linguagem natural é a música.

Esta, segundo Schopenhauer, não exprime o fenômeno, mas unicamente a essência íntima de qualquer fenômeno. Os Gregos passaram por estes dois graus de cultura: a apolínia e a dionisíaca ou trágica.

Nietzsche partindo da ideia pessimista e da concepção schopenhaueriana do mundo demonstra a necessidade de arte, visto existir no homem, naturalmente e positivamente infeliz, a necessidade de satisfazer ao próprio espírito com alguma visão que lhe permita viver idealmente uma série de estados psicológicos que a vida mesma não lhe deixa experimentar em toda a sua extensão e intensidade. Só a arte pois pode fingir ao redor do espírito uma atmosfera de sonho e de êxtase, em que ele esquece as lutas imperiosas e as dolorosas exigências da vida.

A verdade é por si mesma inconsciente para recuperar a felicidade e o repouso.

Todo espírito que sofre na vida, não pode descansar senão na serena aparência que lhe oferece a arte; a qual nos é dada a fim de que, pela tensão a que está sujeito o nosso espírito na ânsia das lutas quotidianas, não se nos quebre o arco da vida. Nada pode substituir a ação e a função calmante da arte; nem mesmo a verdade cujo valor Nietzsche contesta; nem a filosofia, nem o estudo da história.

$\mathrm{O}$ meio principal que a arte deve empregar para alcançar o seu fim é a inocência no sentido que ela, livre e inocente em si, deve 
Mascello, L.

ajudar o homem a se purificar e a se livrar de qualquer culpabilidade necessária e fatal. Outro meio de que se serve a arte para procurar a felicidade do homem é a união íntima entre o espírito do artista e a realidade das coisas exteriores, de tal sorte que ele deve exercer uma fascinação atraente e funesta sobre o observador, arrebatando-o para um elemento misterioso e ardente.

Frederico Nietzsche desenvolvendo outra teoria de Schopenhauer, que considera a tragédia como a forma suprema de poesia, afirma que na arte trágica convergem e assomam todas as vantagens das outras artes e que mais atrativo da tragédia está na crueldade. Entretanto a música é a forma mais apta para explicar e desenvolver todos os sentidos e emoções que uma ação trágica pode despertar na alma do espectador; e assim como numa ação cantada para ser experimentada precisa de um tempo maior do que uma paixão falada, da mesma maneira a música produz numa como extensão do sentimento.

"O men ideal, conclui ele, seria na música cujo maior encanto consistisse na ignorância do bem e do mal; na música vibrante e trêmula de alguma saudade de marinheiro, de alguma sombra dourada, de alguma lembrança terrena; uma arte que absorvesse em si mesma, de uma distância enorme, todas as cores de um mundo moral que desaparece, de um mundo feito quase incompreensível e no mesmo tempo hospital e profundo para receber em si os trânsfugas tardios".

Nietzsche encontra na música de Wagner uma luminosa transformação das suas teorias estéticas, - que aliás são as de Wagner mesmo e de Schopenhauer; e olha para o teatro de Bayreuth como para uma pátria estética, afirmando que no reino de arte o fenômeno wagneriano deve comover e renovar toda a civilização moderna. $\mathrm{Na}$ arte deste grande maestro manifesta-se um espírito cheio de amor e de persuasão, inimigo de qualquer violência e de qualquer escravidão. Este espírito bafeja e palpita na música de Wagner derramando por toda parte um como saudável orvalho de pacificação. O maestro soube também levantar e enobrecer o destino 
da história e da filosofia, das quais ele fez germinar uma força de vontade mais enérgica e inflexível. Contribuiu à helenização do mundo, restaurando e renovando, por meio da sua arte, o espírito e a cultura grega. Na imagem que nos apresenta a obra-prima trágica de Bayreuth nós vemos a luta dos indivíduos contra tudo aquilo que se opõe a eles debaixo da forma de uma necessidade invencível. A tragédia musical de Wagner alcançou também revelar o homem em si mesmo, nas suas lutas íntimas e nas relações com o destino supremo do mundo. Não bastando mais linguagem, assim como hoje se usa, para exprimir as lutas, as penas, as mágoas, os sentimentos dos que sofrem, a música socorre a esta falta e ajuda o homem a externar-se a si mesmo, dando à sua expressão uma extraordinária força de comunicação com as outras almas.

\begin{abstract}
Article published in the Journal of Recife, 10 November 1911. In it the author shows motivated to write about Nietzsche because of the numerous publications about him, as the biography brought to the public by philosopher's sister, Elisabeth Förster. Talks so just quickly about the life of the philosopher, since your goal is to point out some defects and misconceptions in its aesthetic. Then passes, to an approach the Origins of Tragedy using the book of Ettore G. Zoccoli and Attillio Corsi.
\end{abstract}

Keywords: Nietzsche - aesthetic - Origins of Tragedy 
